\title{
STUDI KOMPUTASI EFEK SONOFISIKA DARI GELEMBUNG MIKRO TERHADAP DEFORMASI LAPISAN LOGAM
}

\author{
DAVID $^{1, *}$, FERRY FAIZAL ${ }^{1,2}$, SAHRUL HIDAYAT $^{1}$ \\ ${ }^{I}$ Departemen Fisika, FMIPA, Universitas Padjadjaran \\ Jl. Raya Bandung-Sumedang Km.21 Jatinangor 45363, Sumedang, Jawa Barat \\ ${ }^{2}$ Pusat Unggulan Iptek Perguruan Tinggi Nano Powder Fungsional (Finder U-CoE) \\ Universitas Padjadjaran, Jl. Raya Bandung-Sumedang Km 21 Jatinangor, 45363, Jawa Barat \\ *email : david18001@mail.unpad.ac.id
}

\begin{abstract}
Abstrak. Siklus kavitasi terjadi ketika gelembung mikro diberikan paparan gelombang ultrasonik, yang merupakan fase pengembangan, osilasi, dan pecahnya gelembung di zat cair. Saat pecah, gelembung mikro akan menghasilkan efek sonofisika berupa tekanan dan suhu yang tinggi, yang dapat digunakan untuk mendefromasi permukaan bahan. Telah dilakukan simulasi berdasarkan model dinamika gelembung Rayleigh-Plesset untuk menginvestigasi pengaruh jari-jari awal gelembung terhadap efek sonofisika yang dihasilkan, dan dampaknya terhadap deformasi lapisan logam. Hasil simulasi menyatakan bahwa gelembung dengan jari-jari awal yang kecil memiliki siklus osilasi yang lebih intens dan menghasilkan efek sonofisika yang lebih besar, sehingga memiliki efektivitas yang lebih tinggi untuk mendeformasi lapisan logam.
\end{abstract}

Kata kunci: Kavitasi, Gelembung Mikro, Ultrasonik, Sonofisika, Logam

\begin{abstract}
A cavitation cycle occurs when the microbubble is exposed to an ultrasound field, which is a phase of the formation, growth, oscillation, and collapse of bubbles in a liquid. When a bubble collapses, it will produce sono-physical effects in the form of high pressure and temperature, which can be used to deform the surface of the surrounding material. A simulation based on Rayleigh-Plesset model on bubble dynamics is conducted to investigate the effect of the initial bubble radii on the resulting sonophysical effects, and its impact on metal surface deformation. The simulation results state that bubbles with smaller initial radii have more intense oscillation cycles and produce bigger sono-physical effects, so they have higher effectiveness for deforming metal films.
\end{abstract}

Keywords: Cavitation, Microbubble, Ultrasound, Sonophysics, Metal

\section{Pendahuluan}

Pada era modern ini, banyak teknologi maju yang digunakan untuk pengembangan berbagai inovasi, salah satunya melalui pemanfaatan gelombang ultrasonik. Gelombang ultrasonik adalah gelombang akustik yang memiliki frekuensi lebih besar dari $20 \mathrm{kHz}$, dan tidak dapat didengar oleh manusia. Karena memiliki frekuensi gelombang yang tinggi, ultrasonik banyak digunakan pada reaksi degradasi pewarna, pengolahan air limbah, desinfeksi air minum, deaktivasi bakteri, sampai proses pembersihan polutan dan partikel berukuran mikron dari permukaan padatan seperti logam [1] yang dapat diterapkan pada pembersihan alat-alat kedokteran dan perhiasan. Meskipun tergolong ke dalam material yang paling kuat (relatif terhadap keramik dan polimer), logam memiliki sifat mekanis yang berbeda- 
beda untuk tiap jenisnya. Oleh sebab itu, perlu dikaji ketahanan berbagai jenis logam ketika berada pada proses pembersihan ultrasonik melalui siklus kavitasi.

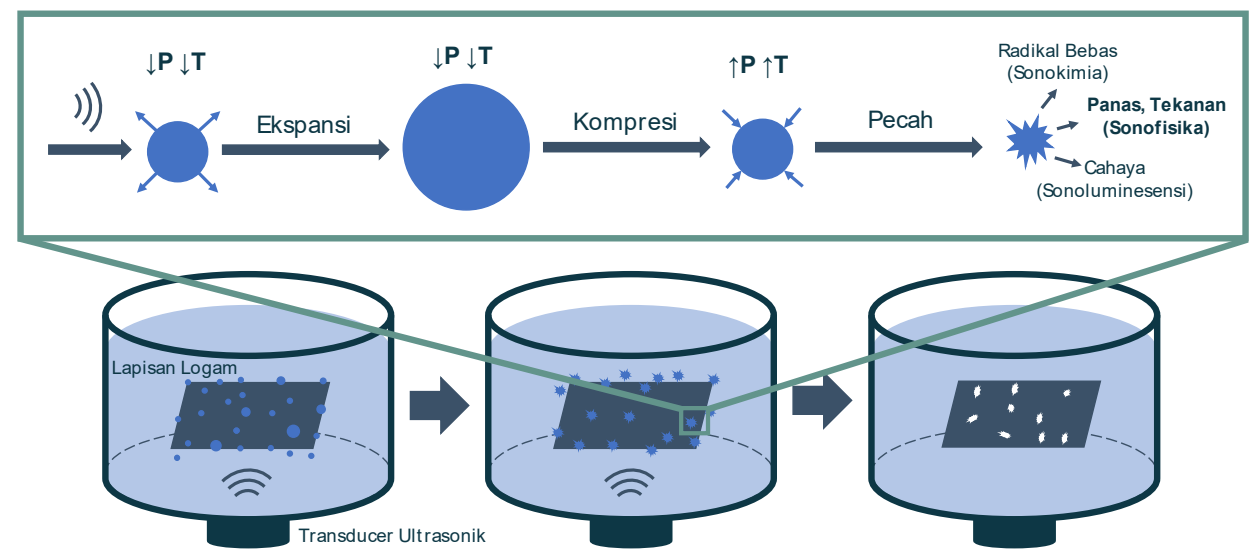

Gambar 1. Dinamika Gelembung pada Medan Ultrasonik

Kavitasi adalah peristiwa terbentuknya gelembung-gelembung uap di dalam zat cair sebagai akibat turunnya tekanan cairan di bawah tekanan uap jenuhnya [2]. Gelembung pada cairan terbentuk melalui proses difusi gas yang terlarut pada cairan ke nukleasi, yaitu rongga dalam cairan, baik itu celah pada permukaan bahan atau bagian kecil yang tidak ditempati oleh cairan. Ukuran gelembung bergantung pada tekanan dan suhu di sekitarnya. Ketika tekanan cairan di sekitar rongga rendah, kelarutan gas dalam zat cair menjadi berkurang sehingga memudahkan gas untuk berdifusi ke dalam rongga untuk membentuk gelembung yang besar. Sebaliknya jika suhu cairan meningkat, ukuran gelembung dan kelarutan gas dalam cairan ikut menurun [3]. Gelembung dengan ukuran 1-100 mikrometer disebut gelembung mikro. Pada saat zat cair terpapar gelombang ultrasonik, terjadi proses pengembangan, osilasi, dan pecahnya gelembung gas karena cairan tersebut mengalami siklus ekspansi (rarefaction) dan kompresi (compression) dari tekanan akustik seperti tampak pada Gambar 1. Pada saat siklus ekspansi, tekanan cairan menjadi rendah sehingga gelembung membesar. Kemudian pada siklus kompresi, gelembung akan termampatkan, hingga akhirnya pecah [4].

Rayleigh berupaya menjelaskan fenomena pecahnya gelembung dalam penelitiannya pada tahun 1917 [5]. Fenomena kavitasi stabil dari gelembung gas kemudian dijelaskan oleh Plesset [6], sehingga disebut persamaan Rayleigh-Plesset. Untuk menyederhanakan model, efek termal gelombang ultrasonik, perpindahan panas dan massa melalui dinding gelembung, perubahan fase dan reaksi kimia diabaikan dan hanya mempertimbangkan gerakan radial gelembung [7]. Bentuk awal persamaan Rayleigh-Plesset ini mengabaikan efek viskositas serta kompresibilitas media sekitarnya, yang kemudian dilengkapi oleh Keller dan Miksis [8]. Persamaan gerak gelembung Keller-Miksis adalah:

$$
\begin{aligned}
& \rho_{L}\left(R \ddot{R}+\frac{3}{2} \dot{R}^{2}\right)=P_{\text {ext }}(t)-\frac{2 \sigma}{R}-\frac{4 \mu_{L} \dot{R}}{R}+P_{\text {int }}(R)\left(1-\frac{3 \kappa}{c} \dot{R}\right) \\
& P_{\text {ext }}(t)=p_{g}-p_{0}-p_{a} \cos (2 \pi f t)
\end{aligned}
$$




$$
P_{\text {int }}(R)=\left(p_{0}-p_{g}+\frac{2 \sigma}{R}\right)\left(\frac{R_{0}}{R}\right)^{3 \kappa}
$$

di mana $R(t)$ adalah jari-jari gelembung, $R_{0}$ adalah jari-jari awal/kesetimbangan, $\kappa$ adalah eksponen dari hubungan barotropik, $\rho_{L}$ adalah densitas zat cair, $\mu_{L}$ adalah viskositas cairan, $p_{0}$ adalah tekanan fluida statis, $p_{g}$ adalah tekanan gas, $p_{a}$ adalah amplitudo tekanan akustik, $\sigma$ adalah tegangan permukaan antar permukaan gelembung dengan zat cair, $c$ adalah cepat rambat gelombang akustik pada zat cair.

Ketika pecah, suhu dan tekanan pada daerah gelembung dapat mencapai nilai yang sangat tinggi. Nilai tekanan dalam gelembung dapat diperoleh dari persamaan (3), sedangkan suhu gelembung dapat diperoleh dari persamaan berikut:

$$
T_{g}=T_{0}\left(\frac{R_{\max }}{R}\right)^{\kappa-1}
$$

Dengan $T_{0}$ adalah suhu awal zat cair dan $R_{\max }$ adalah jari-jari maksimal gelembung. Nilai tekanan dan suhu akan maksimal saat gelembung pertama kali pecah/sebelum rebound pertama untuk tiap periode osilasi. Akibat suhu dan tekanan ekstrem tersebut, dihasilkanlah efek sonokima dan efek sonofisika. Efek sonokimia adalah proses produksi radikal bebas, spesies reaktif untuk proses degradasi/oksidasi, polimerisasi, dan sintesis nanopartikel, dari reaksi pirolisis molekul air akibat suhu tinggi. Sedangkan efek sonofisika merupakan proses pembentukan turbulensi dan shock wave akibat gerakan transient gelembung [9], dan dapat memicu deformasi pada permukaan material yang berada di sekitarnya.

Struktur material dapat berubah bentuk secara geometris akibat penempatan beban luar dan perubahan temperatur. Saat bahan terus mengalami penambahan tegangan sampai melebihi batas elastisnya, maka bahan akan mengalami perubahan bentuk secara permanen hingga akhirnya terjadinya patahan. Logam, yang merupakan material dengan kekuatan terbesar, jika dikenai tegangan berulang akan mengalami kerusakan pada tegangan yang jauh lebih rendah dibandingkan yang dibutuhkan untuk menimbulkan perpatahan [10]. Begitupun dengan pengaruh suhu,ketika diberikan suhu tinggi, kekuatan dari logam menjadi menurun akibat mengalami pemuaian hingga akhirnya akan meleleh. Oleh sebab itu, penelitian ini bertujuan untuk menginvestigasi seberapa besar efek sonofisika yang dapat dihasilkan dari gelembung mikro tunggal dan efektifitasnya untuk mendeformasi lapisan logam.

\section{Metode Penelitian}

Percobaan dilakukan dengan mencari solusi persamaan Rayleigh-Plesset, sehingga diperoleh besar jari-jari untuk setiap waktu, nilai tekanan dan suhu gelembung seperti tampak pada Gambar 2. Solusi persamaan diperoleh menggunakan solver scipy.integrate.odeint() dalam package Python SciPy, dengan timestep (dt) sebesar $2,5 \times 10^{-10}$, dan nilai parameter persamaan pada Tabel 1 . Dengan parameter yang sama, simulasi dilakukan dengan variasi $R_{0}$ sebesar 10 - $30 \mu \mathrm{m}$.

Tabel 1. Parameter Persamaan Rayleigh-Plesset

\begin{tabular}{lcc}
\hline \multicolumn{1}{c}{ Parameter } & Simbol & Nilai \\
\hline Eksponen hubungan barotropik & $\kappa$ & $1,33 \mathrm{~N} / \mathrm{m}$ \\
Densitas Zat Air & $\rho_{L}$ & $998,2 \mathrm{~kg} / \mathrm{m}^{3}$
\end{tabular}




$\begin{array}{lcc}\text { Viskositas Zat Air } & \mu_{L} & 8,9 \times 10^{-4} \mathrm{~Pa} . \mathrm{s} \\ \text { Tekanan Fluida Statis } & p_{0} & 1 \times 10^{5} \mathrm{~Pa} \\ \text { Tekanan Gas } & p_{g} & 2337 \mathrm{~Pa} \\ \text { Amplitudo Tekanan Ultrasonik } & p_{a} & 1,155 \times 10^{5} \mathrm{~Pa} \\ \text { Frekuensi Ultrasonik } & f & 26,5 \times 10^{3} \mathrm{~Hz} \\ \text { Cepat Rambat Gelombang Akustik di Air } & c & 1480 \mathrm{~m} / \mathrm{s} \\ \text { Tegangan permukaan } & \sigma & 0,0725 \mathrm{~N} / \mathrm{m} \\ \text { Suhu Zat Cair } & T_{0} & 300 \mathrm{~K}\end{array}$

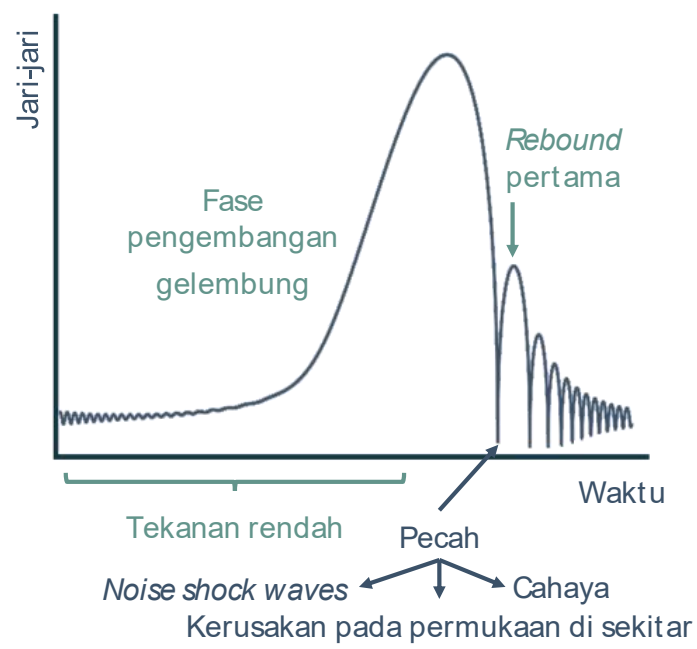

Gambar 2. Solusi Persamaan Rayleigh-Plesset

Setelah solusi diperoleh, nilai tekanan dan suhu maksimum diperoleh dari persamaan (3) dan (4). Besar efektivitas tekanan gelembung untuk mendeformasi lapisan logam diperoleh dari persamaan berikut:

$$
\eta_{\mathrm{g}}=\frac{p_{\max }}{\zeta_{m}} \times 100 \%
$$

Dengan $p_{\max }$ tekanan maksimum gelembung dan $\zeta_{m}$ adalah kekuatan tarik (ultimate tensile strength) dari logam, yaitu $\zeta_{A l}=90 \mathrm{MPa}, \zeta_{C u}=200 \mathrm{MPa}, \zeta_{\text {steel }}=$ $380 \mathrm{MPa}, \zeta_{T i}=520 \mathrm{Mpa}$ [11]. Pengaruh suhu terhadap defromasi logam dilakukan dengan membandingkan suhu maksimal gelembung dengan titik leleh logam. Grafik tegangan-regangan sebuah material diperlihatkan pada Gambar 3. 


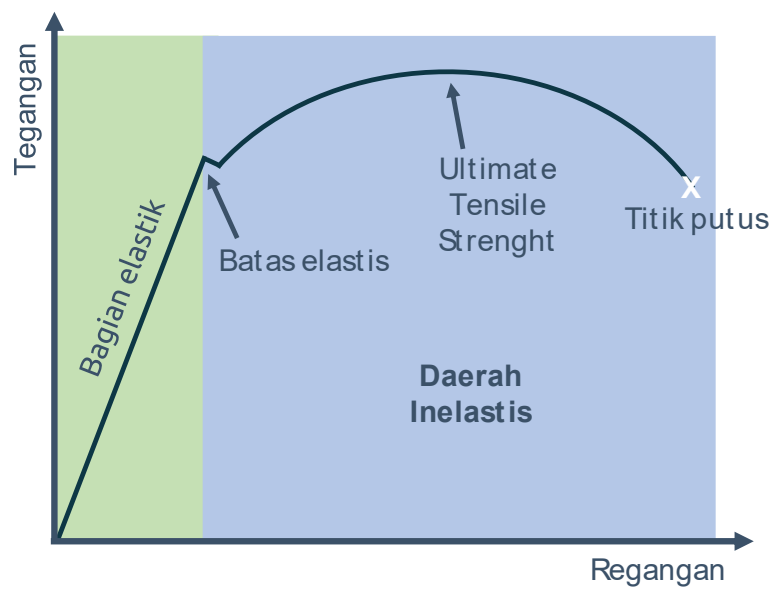

Gambar 3. Grafik Tegangan-Regangan sebuah Material

\section{Hasil dan Pembahasan}

Hasil simulasi dinamika gelembung pada medan ultrasonik ditunjukan pada Gambar 4 untuk masing-masing variasi $R_{0}$ sebesar $10 \mu \mathrm{m}, 20 \mu \mathrm{m}$, dan $30 \mu \mathrm{m}$. Jarijari awal gelembung merupakan parameter penting yang mempengaruhi gerak osilasi gelembung tersebut. Dari Gambar 4 (a, d, g), terlihat bahwa gelembung dengan $R_{0}$ yang lebih kecil mengalami osilasi yang lebih intens untuk satu periode siklus kavitasi. Seperti yang dikutip dari Kumar dan Moholkar [12], gelembung yang lebih kecil memiliki tekanan Laplace yang lebih tinggi sehingga terjadi ekspansi radial yang lebih besar.
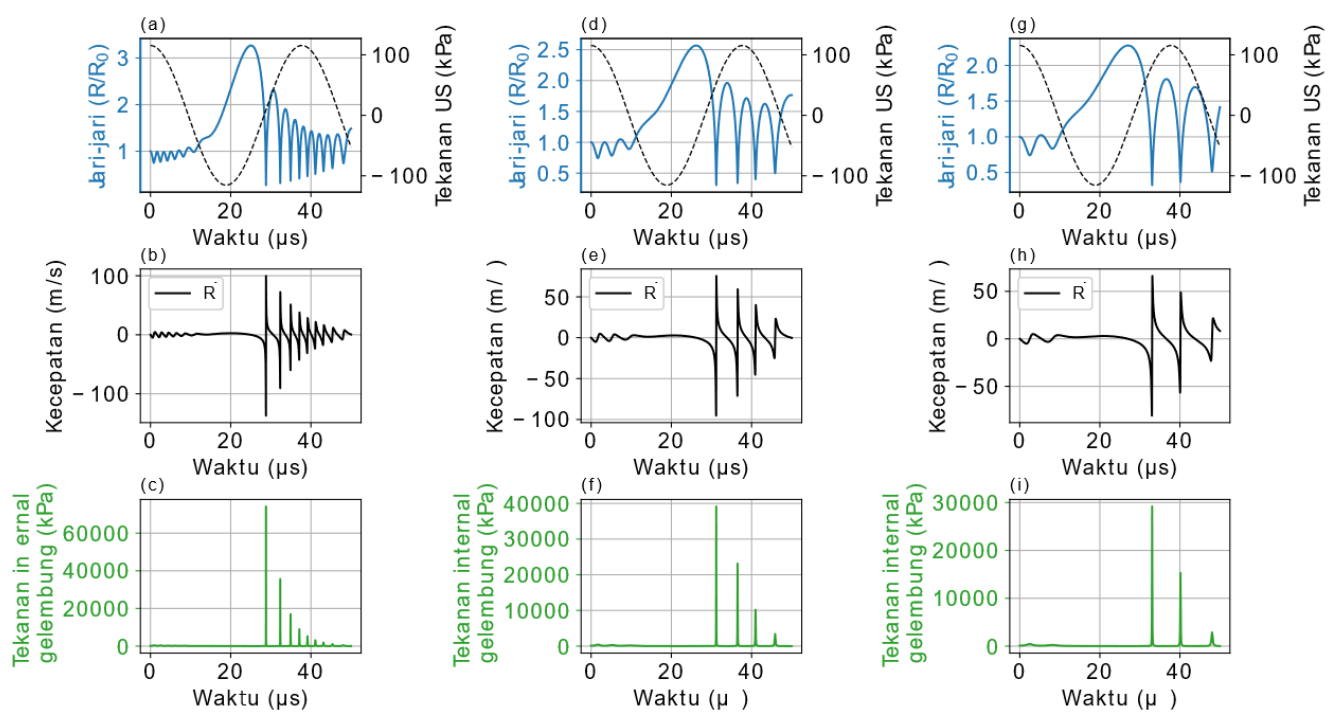

$\mathrm{R}_{0}=10 \mu \mathrm{m}$

$\mathrm{R}_{0}=20 \mu \mathrm{m}$

$\mathrm{R}_{0}=30 \mu \mathrm{m}$

Gambar 4. Dinamika Gelembung dengan R_0 $=10 \mu \mathrm{m}, 20 \mu \mathrm{m}$, dan $30 \mu \mathrm{m}$

Dalam Gambar 4 (b, e, h), kecepatan dinding gelembung ditunjukkan sebagai fungsi dari waktu. Terlihat bahwa kecepatan dinding gelembung meningkat secara 
drastis di tahap akhir pecahnya gelembung sehingga mencapai 136,995 m/s, 95,267 $\mathrm{m} / \mathrm{s}$, dan $80,854 \mathrm{~m} / \mathrm{s}$ untuk masing-masing variasi $R_{0}$ sebesar $10 \mu \mathrm{m}, 20 \mu \mathrm{m}$, dan 30 $\mu \mathrm{m}$. Kecepatan yang tinggi ini menghasilkan pecahan gelembung yang lebih kuat dan menghasilkan suhu dan tekanan yang ekstrem.

Gelembung yang lebih kecil mengalami fase pemecahan yang lebih intens, menghasilkan puncak suhu dan tekanan yang lebih tinggi, seperti yang dapat dilihat dari Gambar 4 (c, f, i). Hal ini disebabkan gelembung dengan radius kecil dapat mengalami banyak siklus akustik sebelum mencapai radius kritisnya untuk pecah, dan akibatnya puncak tekanan dan suhu tertinggi dicapai pada saat gelembung pertama kali pecah/sebelum rebound pertama untuk tiap periode osilasi. Dengan demikian, gelembung yang lebih kecil memberikan kontribusi yang lebih besar pada efek sonofisika. Besar tekanan dan suhu maksimal serta pengaruhnya terhadap deformasi lapisan logam ditunjukan pada Tabel 2.

Tabel 2. Pengaruh Jari-jari Awal terhadap Tekanan dan Deformasi Logam

\begin{tabular}{ccccccc}
\hline & & \multicolumn{5}{c}{ Efektivitas Deformasi oleh Tekanan (\%) } \\
$\mathbf{R}_{\mathbf{0}}(\boldsymbol{\mu m})$ & $\mathbf{P}_{\max }(\mathbf{k P a})$ & $\mathbf{T}_{\max }(\mathbf{K})$ & $\mathbf{A l}$ & $\mathbf{C u}$ & Steel & $\mathbf{T i}$ \\
\hline 10 & 74201,942 & 1570,819 & 82,447 & 37,101 & 19,527 & 14,270 \\
20 & 39155,276 & 1239,136 & 43,506 & 19,578 & 10,304 & 7,530 \\
30 & 29195,703 & 1103,897 & 32,440 & 14,598 & 7,683 & 5,615 \\
\hline
\end{tabular}

Pada Tabel 2, terlihat bahwa gelembung dengan jari-jari awal yang kecil memiliki efektivitas yang lebih tinggi untuk mendeformasi lapisan logam karena dapat menghasilkan tekanan yang lebih tinggi. Dari keempat jenis lapisan logam, gelembung lebih mudah untuk merusak permukaan Aluminium karena unsur tersebut memiliki kekuatan tarik (ultimate tensile strength) yang lebih rendah dibanding logam lainnya. Dari Gambar 5, diperoleh perbandingan suhu maksimal gelembung dengan titik leleh logam, dimana ketiga ukuran gelembung dapat menghasilkan suhu yang tinggi dan melebihi titik leleh logam. Khusus untuk gelembung dengan ukuran $10 \mu \mathrm{m}$, suhu yang dapat dihasilkan melebihi titik leleh dari logam Tembaga. Konsekuensi dari suhu tinggi yang dihasilkan gelembung ini dapat menyebabkan kekuatan dari logam menjadi menurun akibat mengalami pemuaian, bahkan hingga akhirnya meleleh pada bagian tertentu. Tentunya efek sonofisika ini akan jauh lebih lebih besar dan transfer panas menjadi lebih efektif jika jumlah gelembung semakin banyak, karena gelembung mikro tunggal hanya mengemisikan tekanan dan suhu tinggi pada permukaan dengan bagian kecil saja. 


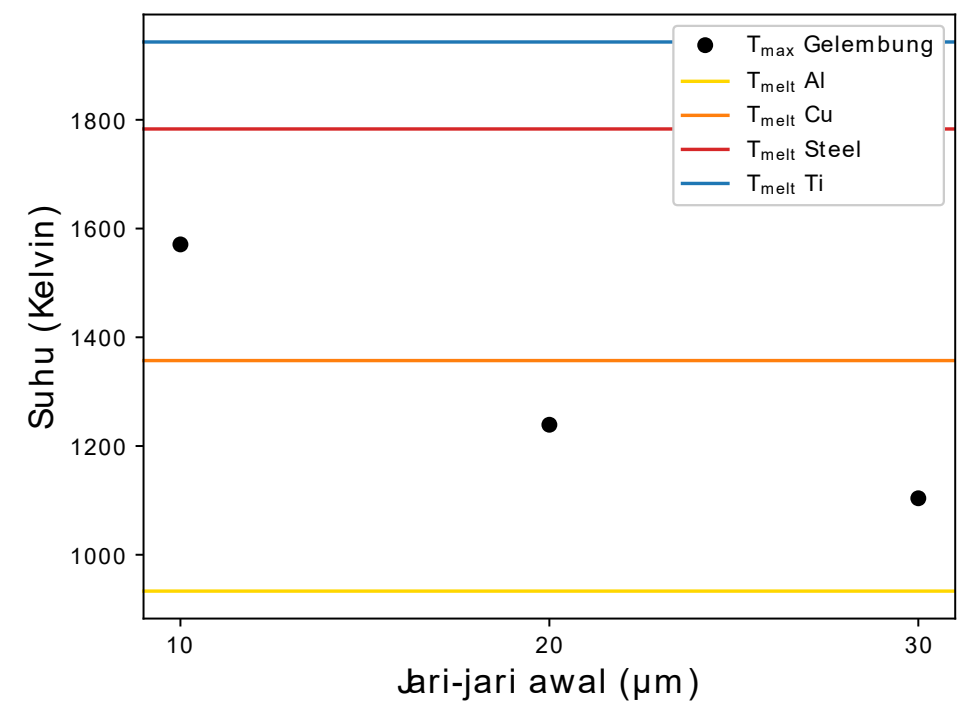

Gambar 5. Perbandingan T_max gelembung dengan titik leleh logam

\section{Kesimpulan}

Pada simulasi ini, diperoleh model yang menggambarkan dinamika gelembung mikro pada saat diberi gelombang ultrasonik dengan berbagai variasi jari-jari awal (R_0). Gelembung yang memilki R_0 yang kecil memiliki siklus osilasi yang lebih intens dan menghasilkan efek sonofisika yang lebih besar, sehingga memiliki efektivitas yang lebih tinggi untuk mendeformasi lapisan logam.

\section{Daftar Pustaka}

1. M.P. Khairunnisa, F. Faizal, E. Miyazawa, K. Masuda, M. Tsukada, I.W. Lenggoro: Detachment of submicron particles from substrates using the suspension-assisted ultrasonic method. Journal of Chemical Engineering of Japan 54(4) (2021), 135-143.

2. B. Fajar, E. Widayati: Investigasi pengaruh kavitasi ultrasonik pada transesterifikasi biodiesel (skala lab) untuk pengembangan ultrasonik mobile reactor. Prosiding SNST Fakultas Teknik 1(1) (2011).

3. E. Stride, C. Coussios: Cavitation and contrast: the use of bubbles in ultrasound imaging and therapy. Proceedings of the Institution of Mechanical Engineers, Part H: Journal of Engineering in Medicine 224(2) (2010), 171-191.

4. K.S. Suslick, D.J. Flannigan: Inside a collapsing bubble: sonoluminescence and the conditions during cavitation. Annu. Rev. Phys. Chem. 59 (2008), 659683

5. L. Rayleigh: Viii. on the pressure developed in a liquid during the collapse of a spherical cavity. The London, Edinburgh, and Dublin Philosophical Magazine and Journal of Science 34(200) (1917), 94-98

6. M.S. Plesset: The dynamics of cavitation bubbles (1949)

7. X. Wang, Z. Ning, M. Lv, C. Sun: Machine learning for predicting the bubblecollapse strength as affected by physical conditions. Results in Physics 25 (2021), 104226

8. J.B. Keller, M. Miksis: Bubble oscillations of large amplitude. The Journal of the Acoustical Society of America 68(2) (1980), 628-633. 
9. V.S. Moholkar: Mathematical models for sonochemical effects induced by hydrodynamic cavitation. Handbook of Ultrasonics and Sonochemistry. 9 Singapore: Springer Science (2015), 1-48.

10. G.E. Dieter, D.J. Bacon: Mechanical Metallurgy vol. 3. McGraw Hill (1976)

11. W.D. Callister Jr, D.G. Rethwisch: Callister's Materials Science and Engineering. John Wiley \& Sons (2020).

12. P. Kumar, V. Moholkar: Numerical assessment of hydrodynamic cavitation reactors using organic solvents. Industrial \& Engineering Chemistry Research 50(8) (2011), 4769-4775. 